\title{
Inclusão de lisina digestível em dietas para leitoas dos 60 aos 100 dias de idade
}

\author{
[Digestible lysine inclusion in diets for gilts from 60 to 100 days of age] \\ G. Gattás ${ }^{1}$, F.C.O. Silva ${ }^{2 *}$, F.F. Barbosa ${ }^{3}$, J.L. Donzele ${ }^{4}$, A.S. Ferreira ${ }^{4}$, \\ R.F.M. Oliveira ${ }^{4}$, P.C. Brustolini ${ }^{4}$ \\ ${ }^{1}$ Rio Branco alimentos - Viçosa, MG \\ ${ }^{2}$ EPAMIG - Viçosa, MG \\ ${ }^{3}$ Agroceres Nutrição Animal - Patos de Minas, MG \\ ${ }^{4}$ Universidade Federal de Viçosa - Viçosa, MG
}

\begin{abstract}
RESUMO
Foi realizado um experimento utilizando-se 300 leitoas, com peso inicial de $25,00 \pm 0,54 \mathrm{~kg}$, para avaliar os efeitos da porcentagem de lisina digestível sobre o desempenho e a composição da carcaça de leitoas dos 60 aos 100 dias de idade. Os animais foram distribuídos em delineamento experimental de blocos ao acaso, com cinco tratamentos 0,$65 ; 0,75 ; 0,85 ; 0,95$ e $1,05 \%$ de lisina digestível, cinco repetições e 12 animais por unidade experimental. Não se observou efeito significativo dos tratamentos sobre o consumo de ração diário e o rendimento de carcaça das leitoas. A porcentagem de lisina da dieta influenciou o consumo de lisina digestível e o ganho de peso diário, que aumentaram de forma linear. O aumento na concentração de lisina digestível da dieta melhorou de forma linear a conversão alimentar e aumentou a quantidade de carne magra da carcaça. A porcentagem de lisina influenciou a espessura de toucinho das leitoas, que reduziu de forma quadrática até a porcentagem estimada de $0,87 \%$ de lisina digestível. A inclusão de $1,05 \%$ de lisina digestível na dieta, correspondente ao consumo de lisina digestível de $18,50 \mathrm{~g} / \mathrm{dia}$, proporciona os melhores resultados de desempenho e quantidade de carne na carcaça de leitoas dos 60 aos 100 dias de idade.
\end{abstract}

Palavras-chave: aminoácido digestível, carcaça, carne magra, espessura de toucinho, fase de crescimento, suínos

\begin{abstract}
The experiment was conducted with 300 gilts with initial weight of $25.00 \pm 0.54 \mathrm{~kg}$, from 60 to 100 days of age, to evaluate the effects of digestible lysine percentages on performance and carcass traits of the animals. The gilts were allotted in a randomized block design, with five treatments (percentages of digestible lysine), five replicates, and twelve animals per experimental unit. The treatments applied were $0.65 ; 0.75 ; 0.85 ; 0.95$ and $1.05 \%$ of digestible lysine. No effects of treatments on the daily feed intake of the gilts were observed. A linear increase on digestible lysine intake as a result of increasing the concentration of digestible lysine in the diet was verified. The increase in dietary digestible lysine concentration resulted in a linear increase of daily weight gain. The increase of digestible lysine concentrations in the diet resulted in a linear improvement of feed conversion and in a linear increase in the amount of lean meat in the carcass. There was no effect of digestible lysine concentration on gilts' carcass traits. The amount of lean meat in the carcass of pigs increased linearly with the increase of the percentage of digestible lysine in the diets. The percentage of digestible lysine influenced the back fat thickness of the gilts which decreased quadratically up to $0.87 \%$ digestible lysine maximum response. The inclusion of $1.05 \%$ digestible lysine in the diet, corresponding to a daily intake of $18.5 \mathrm{~g}$ digestible lysine provides the greatest performance results and amount of lean meat in the carcass of gilts from 60 to 100 days of age.
\end{abstract}

Keywords: amino acid digestibility, carcass, lean, backfat thickness, growth phase, swine

Recebido em 3 de maio de 2011

Aceito em 24 de maio de 2012

*Autor para correspondência (corresponding author)

E-mail: fcosilva@epamig.br 


\section{INTRODUÇÃO}

A lisina tem sido associada às respostas positivas de desempenho e composição de carcaça dos suínos, em especial daqueles selecionados para a deposição de tecido muscular (Yen et al., 1986). Dessa forma, a determinação da exigência deste aminoácido pode ser necessária para definir os padrões de alimentação dos suínos geneticamente selecionados.

Os atuais genótipos de suínos introduzidos no mercado têm como principal característica produtiva a maior deposição de tecido muscular na carcaça. Como o aumento do tecido muscular é o principal objetivo da criação de suínos para o abate, este tem sido o principal critério avaliado por influenciar diretamente as exigências de aminoácidos essenciais, principalmente de lisina.

As linhagens de suínos podem apresentar diferentes exigências de lisina, sendo que uma linhagem com alta capacidade para a síntese de tecido muscular tem maior exigência de lisina digestível por kcal de energia disponível que linhagens de menor capacidade de deposição deste tecido. Entretanto, o genótipo não só afeta a capacidade de deposição de tecido muscular, mas também tem influência na eficiência de deposição de proteína e no peso em que se atinge o platô de deposição de carne. Além da genética, as necessidades de lisina podem ser influenciadas pelo sexo, peso corporal e ambiente (temperatura, status sanitário, etc.), que, portanto, devem ser considerados também no estabelecimento das necessidades de lisina (Abreu et al., 2007).

Com relação ao sexo, tem sido verificado que não só o desempenho mas as características de qualidade da carcaça também apresentam diferenças entre machos castrados e fêmeas. As fêmeas, normalmente, são mais exigentes que os machos castrados devido à menor capacidade destes em incorporar aminoácidos aos tecidos musculares, em razão da ausência de hormônios sexuais (Souza, 1997). Machos castrados ganham mais peso e apresentam maior consumo do que as fêmeas, porém essas ganham peso de forma mais eficiente, apresentando menos gordura e maior porcentagem de músculo na carcaça. Devido às diferenças no consumo diário de ração e na partição de nutrientes para ganho de peso, as fêmeas podem exigir maior concentração de lisina na ração. Desse modo, grupos sexuais de suínos (machos castrados e fêmeas) podem apresentar diferenças nas necessidades nutricionais em razão do padrão de consumo.

Assim, entendeu-se ser necessário determinar a exigência nutricional de lisina digestível, de acordo com conceito de proteína ideal, para fêmeas suínas dos 60 aos 100 dias de idade, com base nos dados de desempenho e características de carcaça.

\section{MATÉRIAL E MÉTODOS}

O experimento foi realizado entre março e maio de 2006. Foram utilizadas 300 leitoas de linhagem comercial com alto potencial genético para deposição de carne na carcaça, com peso inicial de $25,00 \pm 0,54 \mathrm{~kg}$ e 60 dias de idade, distribuídas em delineamento experimental em blocos ao acaso, com cinco tratamentos (níveis de lisina digestível na ração), cinco repetições, com doze animais por unidade experimental. O critério para distribuição dos animais dentro das repetições foi o peso inicial. Os tratamentos consistiram de diferentes níveis de lisina digestível obtidos a partir da inclusão de quatro níveis de L-lisina $\mathrm{HCl}(78,8 \%)$, resultando em dietas experimentais com 0,$65 ; 0,75 ; 0,85 ; 0,95 \mathrm{e}$ $1,05 \%$ de lisina digestível.

Os animais foram alojados em baias coletivas com comedouro linear com $2,0 \mathrm{~m}$ de comprimento, $0,25 \mathrm{~m}$ de largura e $0,15 \mathrm{~m}$ de altura, possibilitando o consumo por seis animais simultaneamente, e bebedouros tipo chupeta, sendo um do tipo pendular por baia, em galpão de alvenaria, com piso compacto dotado de lâmina de água e cobertura com telha metálica.

A ventilação e a temperatura do ambiente foram controladas por abertura e fechamento de cortinas. O registro diário da temperatura foi realizado utilizando-se termômetros de máxima e mínima, instalados em uma baia vazia a uma altura correspondente à meia altura do corpo dos animais. As dietas experimentais foram formuladas à base de milho e farelo de soja e suplementadas com minerais e vitaminas, para atender as exigências dos animais de acordo com Rostagno et al. (2005), exceto em relação à lisina. A exigência do quarto aminoácido limitante (triptofano) foi atendida mediante 
variação da proporção de milho e de farelo de soja. Em cada porcentagem de lisina avaliada foram verificadas as relações aminoacídicas entre todos os aminoácidos essenciais digestíveis e a lisina digestível para que estas correspondessem, no mínimo, às relações preconizadas por Rostagno et al. (2005) na proteína ideal para suínos na fase inicial. A digestibilidade dos aminoácidos industriais adicionados à dieta foi considerada $100 \%$. Na Tab. 1, são apresentadas as composições centesimais e nutricionais das rações experimentais.
Ração e água foram fornecidas à vontade aos animais durante o período experimental, sendo as rações pesadas diariamente, enquanto as sobras de ração foram coletadas diariamente, armazenadas e pesadas no final do período experimental, para determinação do consumo de ração diário. Os animais foram pesados no início e no final do período experimental, que teve a duração de 40 dias, para determinação do ganho de peso diário.

Tabela 1. Composições centesimais e nutricionais calculadas das dietas experimentais

\begin{tabular}{|c|c|c|c|c|c|}
\hline \multirow[t]{2}{*}{ Ingrediente } & \multicolumn{5}{|c|}{ Lisina digestível (\%) } \\
\hline & 0,65 & 0,75 & 0,85 & 0,95 & 1,05 \\
\hline Milho moído & 73,33 & 73,20 & 72,01 & 69,02 & 65,94 \\
\hline Farelo de soja (45\%) & 21,10 & 21,10 & 22,10 & 25,00 & 28,00 \\
\hline Óleo de soja degomado & 2,35 & 2,35 & 2,35 & 2,35 & 2,35 \\
\hline Fosfato bicálcico & 1,95 & 1,95 & 1,95 & 1,95 & 1,95 \\
\hline Calcário calcítico & 0,25 & 0,25 & 0,25 & 0,25 & 0,25 \\
\hline Sal comum & 0,42 & 0,42 & 0,42 & 0,42 & 0,42 \\
\hline L-lisina $(78,8 \%)$ & - & 0,13 & 0,23 & 0,27 & 0,30 \\
\hline DL-metionina & - & - & 0,03 & 0,06 & 0,09 \\
\hline L-treonina $(98,5 \%)$ & - & - & 0,06 & 0,08 & 0,10 \\
\hline Premix mineral vitamínico ${ }^{1}$ & 0,60 & 0,60 & 0,60 & 0,60 & 0,60 \\
\hline Total & 100,00 & 100,00 & 100,00 & 100,00 & 100,00 \\
\hline \multicolumn{6}{|l|}{ Composição nutricional calculada $^{2}$} \\
\hline Energia digestível (kcal/kg) & 3.476 & 3.478 & 3.479 & 3.479 & 3.479 \\
\hline Energia metabolizável (kcal/kg) & 3.301 & 3.302 & 3.302 & 3.297 & 3.292 \\
\hline Proteína bruta $(\%)$ & 15,84 & 16,08 & 16,62 & 17,64 & 19,68 \\
\hline Lisina total $(\%)$ & 0,75 & 0,85 & 0,95 & 1,06 & 1,16 \\
\hline Lisina digestível $(\%)^{3}$ & 0,65 & 0,75 & 0,85 & 0,95 & 1,05 \\
\hline Metionina+cistina digestível $(\%)^{3}$ & 0,44 & 0,44 & 0,48 & 0,53 & 0,59 \\
\hline Metionina digestível $(\%)^{3}$ & 0,22 & 0,22 & 0,25 & 0,29 & 0,34 \\
\hline Treonina digestível $(\%)^{3}$ & 0,47 & 0,47 & 0,54 & 0,60 & 0,66 \\
\hline Triptofano digestível $(\%)^{3}$ & 0,14 & 0,14 & 0,15 & 0,16 & 0,18 \\
\hline Valina digestível $(\%)^{3}$ & 0,61 & 0,61 & 0,63 & 0,67 & 0,72 \\
\hline Arginina digestível $(\%)^{3}$ & 0,92 & 0,92 & 0,95 & 1,03 & 1,11 \\
\hline Cálcio $(\%)$ & 0,64 & 0,64 & 0,64 & 0,64 & 0,65 \\
\hline Fósforo Total (\%) & 0,56 & 0,56 & 0,56 & 0,57 & 0,59 \\
\hline Fósforo disponível (\%) & 0,43 & 0,43 & 0,43 & 0,43 & 0,43 \\
\hline Sódio $(\%)$ & 0,20 & 0,20 & 0,20 & 0,20 & 0,20 \\
\hline Potássio (\%) & 0,61 & 0,61 & 0,62 & 0,67 & 0,71 \\
\hline Cloro $(\%)$ & 0,30 & 0,33 & 0,34 & 0,35 & 0,36 \\
\hline
\end{tabular}

${ }^{\mathrm{T}}$ Conteúdo/kg de produto: $\mathrm{Ca}$ - 98,80g; Co - 185,0mg; Cu - 15.750mg; Fe - 26.250mg; I - 1.470mg; Mn - 41.850mg; Zn - 77.999mg; ácido fólico (folic acid) - 351,75mg; ácido pantotênico (pantothenic acid) - 3.500mg; antioxidante (BHT) - 1.500mg; biotina (biotine) - 18,90mg; colina (choline) - 52,50g; niacina (niacin) - 6.930mg; vit. B6 - 630mg; vit. B2 - 1.400mg; Se - 131,25mg; vit. B1 - 350mg; vit. A - 1.750 UI; vit. B12 - 8.750,70mcg; vit. D3 - 700.000 UI; vit. E - 3.500mg; vit. K3 - 700mg.

${ }^{2}$ Composição calculada segundo Rostagno et al. (2005).

${ }^{3}$ Valores estimados com base nos coeficientes de digestibilidade dos aminoácidos dos ingredientes, de acordo com Rostagno et al. (2005). 
Ao final do experimento, após jejum de 12 horas, o animal de peso mais próximo ao peso médio de cada repetição foi novamente pesado e transportado até o abatedouro, onde foi abatido conforme procedimentos da indústria para verificação de características de carcaça. Foram avaliadas as seguintes características de carcaça: rendimento de carcaça, quantidade de carne e espessura de toucinho.

As análises estatísticas das variáveis de desempenho (ganho de peso, consumo de ração e conversão alimentar) e das características de carcaça (rendimento de carcaça, quantidade de carne e espessura de toucinho) foram realizadas por meio do programa computacional SAEG (Sistema..., 2009). A estimativa da exigência de lisina digestível foi determinada com base nos resultados de desempenho e carcaça, utilizandose os modelos linear e/ou quadrático, conforme o melhor ajuste obtido para cada variável.

\section{RESULTADOS E DISCUSSÃO}

As temperaturas, mínima e máxima, no interior do galpão durante o período experimental mantiveram-se, respectivamente, entre $16,9 \pm 4,32^{\circ} \mathrm{C}$ e $28,6 \pm 2,97^{\circ} \mathrm{C}$. Considerando-se que a faixa ideal de temperatura para suínos na fase de crescimento sugerida por Coffey et al. (2000) está entre 16 e $24^{\circ} \mathrm{C}$, constatou-se, com base na variação da temperatura ocorrida na condução do experimento, que os animais podem ter sido submetidos a período de estresse térmico. Entretanto, as instalações possuíam lâmina d'água, o que provavelmente possibilitou a expressão do seu máximo potencial genético para produção.

Os resultados de desempenho e de consumo de lisina digestível diário de leitoas, dos 60 aos 100 dias de idade, em função dos níveis de lisina da ração, encontram-se na Tab. 2. Não foi verificado efeito $(\mathrm{P} \geq 0,05)$ dos tratamentos sobre o consumo de ração diário (CRD) das leitoas. Estes resultados são semelhantes aos observados por Haese et al. (2006), que, avaliando níveis de lisina digestível entre 0,87 e $1,26 \%$, não observaram influência significativa dos tratamentos sobre o CRD de leitoas dos 60 aos 100 dias de idade. Da mesma forma, Donzele et al. (1994), ao avaliarem inclusão de lisina total, 0,63 a $1,03 \%$, não verificaram efeito dos tratamentos sobre CRD das leitoas. Souza (1997) e Fontes et al. (2000), também não observaram efeito da concentração de lisina na dieta sobre o CRD de suínos na fase de crescimento.

Tabela 2. Valores de desempenho e consumo de lisina para leitoas dos 60 aos 100 dias, em função da porcentagem de lisina da dieta

\begin{tabular}{|c|c|c|c|c|c|c|}
\hline \multirow[t]{2}{*}{ Variáveis } & \multicolumn{5}{|c|}{ Lisina digestível (\%) } & \multirow{2}{*}{$\begin{array}{l}\mathrm{CV} \\
(\%)\end{array}$} \\
\hline & 0,65 & 0,75 & 0,85 & 0,95 & 1,05 & \\
\hline Peso médio inicial $(\mathrm{kg})$ & 25,32 & 25,35 & 25,35 & 25,35 & 25,30 & - \\
\hline Peso médio final $(\mathrm{kg})$ & 54,55 & 55,25 & 57,75 & 58,64 & 59,31 & - \\
\hline Consumo de ração diário $(\mathrm{g})$ & 1734 & 1720 & 1766 & 1772 & 1758 & 5,29 \\
\hline Consumo de lisina digestível $(\mathrm{g} / \mathrm{dia})^{1}$ & 11,27 & 12,9 & 15,01 & 16,83 & 18,46 & 4,51 \\
\hline Ganho de peso diário $(\mathrm{g})^{1}$ & 731 & 747 & 810 & 832 & 850 & 4,76 \\
\hline Conversão alimentar $(\mathrm{g} / \mathrm{g})^{1}$ & 2,37 & 2,30 & 2,18 & 2,13 & 2,07 & 2,84 \\
\hline
\end{tabular}

${ }^{1}$ Efeito linear $(\mathrm{P} \leq 0,01)$.

Fontes et al. (2005), ao avaliarem inclusão de lisina total entre 0,80 e $1,20 \%$, constataram efeito quadrático dos tratamentos sobre o CRD de leitoas de alto potencial genético, dos 30 aos $60 \mathrm{~kg}$. Ressalta-se, entretanto, que, nesse estudo, o aumento dos níveis da lisina não foi acompanhado por aumentos nas concentrações dos demais aminoácidos essenciais, o que pode ter resultado em desbalanço de aminoácidos das dietas. Esse fato pode explicar, em parte, a divergência de resultados de CRD em relação aos verificados no presente estudo.
Segundo D’Mello (1993), o não balanceamento de aminoácidos tem como um dos sintomas característicos a diminuição do consumo voluntário de alimento pelos animais. Henry (1985) afirmou que o consumo de alimento pode ser negativamente influenciado por deficiência de aminoácido limitante ou por excessivo suprimento de proteína ou de aminoácidos. No presente estudo, o desbalanço aminoacídico foi minimizado quando se suplementaram as dietas com aminoácidos industriais, mantendo, assim, 
as relações dos principais aminoácidos essenciais digestíveis com a lisina digestível.

Outra possível razão para a não variação significativa do CRD entre os tratamentos pode ser o fato de os suínos em crescimento não ajustarem o CRD para atender a sua demanda nutricional de lisina. De acordo com Baker (1993), a inclusão de até $4 \%$ de lisina na dieta é bem tolerada pelos suínos em crescimento.

Observou-se aumento linear $(\mathrm{P} \leq 0,05)$ do consumo de lisina digestível (CLD) em razão do aumento do nível de lisina das rações, segundo a equação $\hat{\mathrm{Y}}=-0,8897+18,4609 \mathrm{X}, \mathrm{r}^{2}=0,96$ (Tab. 2). Este resultado está coerente com aqueles obtidos por Fontes et al. (2000; 2005) e Silva et al. (2009), ao avaliarem níveis crescentes de lisina em rações para suínos fêmeas em crescimento e machos castrados em terminação, respectivamente. $\mathrm{O}$ aumento do CLD pode ter ocorrido em razão direta do aumento de suas concentrações nas rações, uma vez que o consumo voluntário de ração pelos animais não variou significativamente entre os tratamentos.

A porcentagem de lisina da dieta influenciou $(\mathrm{P} \leq 0,01)$ o ganho de peso diário (GPD), que aumentou de forma linear (Tab. 2) devido ao aumento da concentração de lisina digestível nas dietas, segundo a equação $\hat{\mathrm{Y}}=0,5186+$ $0,3241 X, r^{2}=0,95$.

De forma semelhante, Friesen et al. (1994), ao avaliarem a porcentagem de lisina digestível entre 0,54 e $1,04 \%$ para leitoas dos 34 aos $55 \mathrm{~kg}$, constataram efeito linear sobre o GPD de leitoas. Entretanto, a inclusão de lisina digestível que proporcionou o melhor resultado de GPD foi a de $0,95 \%$, correspondente a um consumo de lisina digestível diário de 16,93g.

Em contrapartida, Donzele et al. (1994) e Fontes et al. (2000) não observaram efeito de concentrações crescentes de lisina total nas dietas sobre o ganho de peso de leitoas dos 30 aos $60 \mathrm{~kg}$.

A diferença de respostas de GPD de suínos, constatada entre os trabalhos, pode estar relacionada, entre outros fatores, a diferenças no padrão genético dos animais quanto ao potencial de crescimento muscular e ao sistema de alimentação (Stahly et al., 1991), ao perfil de aminoácidos da dieta, ao estado de saúde e ao sexo dos animais e ao ambiente. Segundo Friesen et al. (1994), além da elevada capacidade de deposição de proteína, suínos melhorados possuem ainda menor consumo de ração, o que pode levar à necessidade de maiores concentrações de lisina na dieta. Considerandose os resultados de ganho de peso diário dos animais, no presente estudo, pode-se inferir que fêmeas suínas com alto potencial para deposição de carne na carcaça na fase de inicial de crescimento respondem a concentrações crescentes de lisina da dieta até o ponto determinado pelo potencial do genótipo.

$\mathrm{O}$ aumento da porcentagem de lisina digestível da ração melhorou $(\mathrm{P} \leq 0,01)$ a conversão alimentar (CA) de maneira linear, conforme a equação $\hat{\mathrm{Y}}=2,8793-0,7868 \mathrm{X}, \mathrm{r}^{2}=0,98$ (Tab. 2). Friesen et al. (1994) e Fontes et al. (2000) também observaram redução linear na CA das leitoas na fase de crescimento em razão do aumento da concentração de lisina digestível da dieta. Já Donzele et al. (1994) e Fontes et al. (2005) observaram efeito quadrático da porcentagem de lisina na dieta sobre a CA dos animais, que melhorou, respectivamente, até a concentração estimada de $0,91 \%$ e $1,16 \%$ de lisina total, enquanto Haese et al. (2006) não constataram efeito significativo do aumento da porcentagem de lisina da dieta sobre a CA de leitoas dos 60 aos 100 dias de idade.

O valor de $1,05 \%$ de lisina digestível, o qual correspondeu ao consumo de lisina digestível estimado de 18,49g/dia, que, neste estudo, proporcionou o melhor resultado de $\mathrm{CA}$, foi maior que a recomendação preconizada pelo NRC National..., (1998) para suínos de 20 a $50 \mathrm{~kg}$, de $0,82 \%$ de lisina digestível. Contudo, foi semelhante ao preconizado, respectivamente, por Rostagno et al. (2005) e Rostagno et al. (2011), para leitoas de 30 a $50 \mathrm{~kg}$, de 1,10 e $1,12 \%$ de lisina digestível, que correspondem ao consumo estimado de 17,8 e $19,8 \mathrm{~g} /$ dia, e aos obtidos por Fontes et al. (2005), os quais verificaram melhor resultado de CA com 1,05\% de lisina digestível, que correspondeu ao consumo de 19,72g/dia. Considerando-se esses resultados, provavelmente a inclusão de $0,82 \%$ de lisina digestível preconizada pelo NRC National..., (1998), para suínos de 60 a 100 dias de idade, não atende às exigências das linhagens comerciais atuais, com 
maior eficiência de ganho em carne magra na carcaça.

A melhora linear do GPD e da CA pode ser explicada em razão de a lisina ser um aminoácido quase exclusivamente direcionado para a síntese proteica. Consequentemente, alterou-se a composição do ganho dos animais, que depositam mais proteína e menos gordura. A alteração na composição do ganho, com maior deposição de proteína em detrimento da de gordura, resulta em melhora na eficiência de utilização do alimento por unidade de ganho de peso, pelo fato de que, na deposição de tecido proteico, ocorre, simultaneamente, maior deposição de água, contrariamente à deposição de tecido adiposo (Hahn et al., 1995).
Os dados de características de carcaça dos suínos alimentados com dietas com diferentes concentrações de lisina digestível estão apresentados na Tab. 3. Não se observou efeito $(\mathrm{P} \geq 0,05)$ da inclusão de lisina na dieta sobre $\mathrm{o}$ rendimento de carcaça das leitoas. Este resultado foi similar ao encontrado por Haese et al. (2011), que avaliaram concentrações de lisina digestível entre 0,87 e 1,26\% para suínos machos castrados dos 60 aos 100 dias de idade. Por outro lado, Gattas et al. (2012) constataram que o aumento da concentração de lisina digestível na dieta para suínos machos castrados dos 60 aos 100 dias de idade influenciou, de forma quadrática, o rendimento de carcaça dos animais, que aumentou até a porcentagem estimada de 0,89\% de lisina digestível, correspondendo ao consumo diário de lisina de 17,28g.

Tabela 3. Características de carcaça de leitoas dos 60 aos 100 dias, em função da porcentagem de lisina digestível da dieta

\begin{tabular}{|c|c|c|c|c|c|c|}
\hline \multirow[t]{2}{*}{ Parâmetro } & \multicolumn{5}{|c|}{ Lisina digestível (\%) } & \multirow{2}{*}{$\begin{array}{l}\text { CV } \\
(\%)\end{array}$} \\
\hline & 0,65 & 0,75 & 0,85 & 0,95 & 1,05 & \\
\hline Rendimento de carcaça (\%) & 72,20 & 70,00 & 70,40 & 69,80 & 69,80 & 6,61 \\
\hline Quantidade de carne $(\mathrm{kg})^{1}$ & 21,83 & 20,97 & 23,35 & 24,68 & 22,76 & 3,82 \\
\hline Espessura de toucinho $(\mathrm{mm})^{2}$ & 11,06 & 11,08 & 8,60 & 9,12 & 11,06 & 12,67 \\
\hline
\end{tabular}

${ }^{1}$ Efeito linear $(\mathrm{P} \leq 0,05) ;{ }^{2}$ Efeito quadrático $(\mathrm{P} \leq 0,05)$.

Foi verificado efeito $(\mathrm{P} \leq 0,05)$ da concentração de lisina sobre a quantidade de carne magra na carcaça das leitoas, que aumentou de forma linear segundo a equação $\hat{\mathrm{Y}}=18,992+4,019 \mathrm{X}$, $\mathrm{r}^{2}=0,41$ (Tab. 3). Fontes et al. (2000), ao utilizarem a metodologia do abate comparativo, constataram melhor resposta de deposição de proteína na carcaça das leitoas em crescimento nos animais que consumiram dietas com $0,93 \%$ de lisina digestível, enquanto Batista et al. (2011) observaram que o aumento da concentração de lisina digestível na dieta melhorou de forma quadrática a deposição de proteína na carcaça até a porcentagem estimada de $1,05 \%$, correspondente a consumo diário de lisina digestível de 21,0g, quando os animais foram mantidos no ambiente com temperatura de $30^{\circ} \mathrm{C}$. Por outro lado, ao avaliarem concentrações de lisina digestível em dietas para fêmea suína em terminação, Haese et al. (2006) não verificaram variação significativa na quantidade de carne na carcaça dos animais entre os tratamentos.

Considerando-se que a deposição de proteína é o principal critério determinante na definição da exigência de lisina dos suínos e que o ambiente térmico também pode influenciar a deposição de carne, pode-se inferir que a variação de resultados observados entre os trabalhos quanto à exigência de lisina digestível dos suínos em crescimento pode estar relacionada à capacidade genética para a deposição de carne magra e aos ambientes térmicos a que os suínos foram submetidos durante a condução dos diferentes trabalhos. Stahly et al. (1994), ao trabalharem com suínos de baixo, médio e alto potencial genético para eficiência alimentar e deposição de carne magra, constataram que os animais de alto potencial exigem níveis mais elevados de lisina na ração para maximizar o desempenho e a deposição de carne magra na carcaça. 
A porcentagem de lisina influenciou $(\mathrm{P} \leq 0,05)$ a espessura de toucinho das leitoas, pois observouse redução de forma quadrática até a porcentagem estimada de $0,87 \%$ (Tab. 3 e Fig. 1), que proporcionou um consumo estimado de $15,23 \mathrm{~g}$ de lisina digestível/dia. Variação de forma quadrática da porcentagem de gordura na carcaça de fêmeas suínas na fase de crescimento em razão do aumento de lisina da dieta também foi observada por Fontes et al. (2005). Diferentemente dos resultados obtidos, Fontes $e t$ al. (2000) e Haese et al. (2006) não observaram efeito da lisina sobre a espessura de toucinho das leitoas na fase de crescimento.

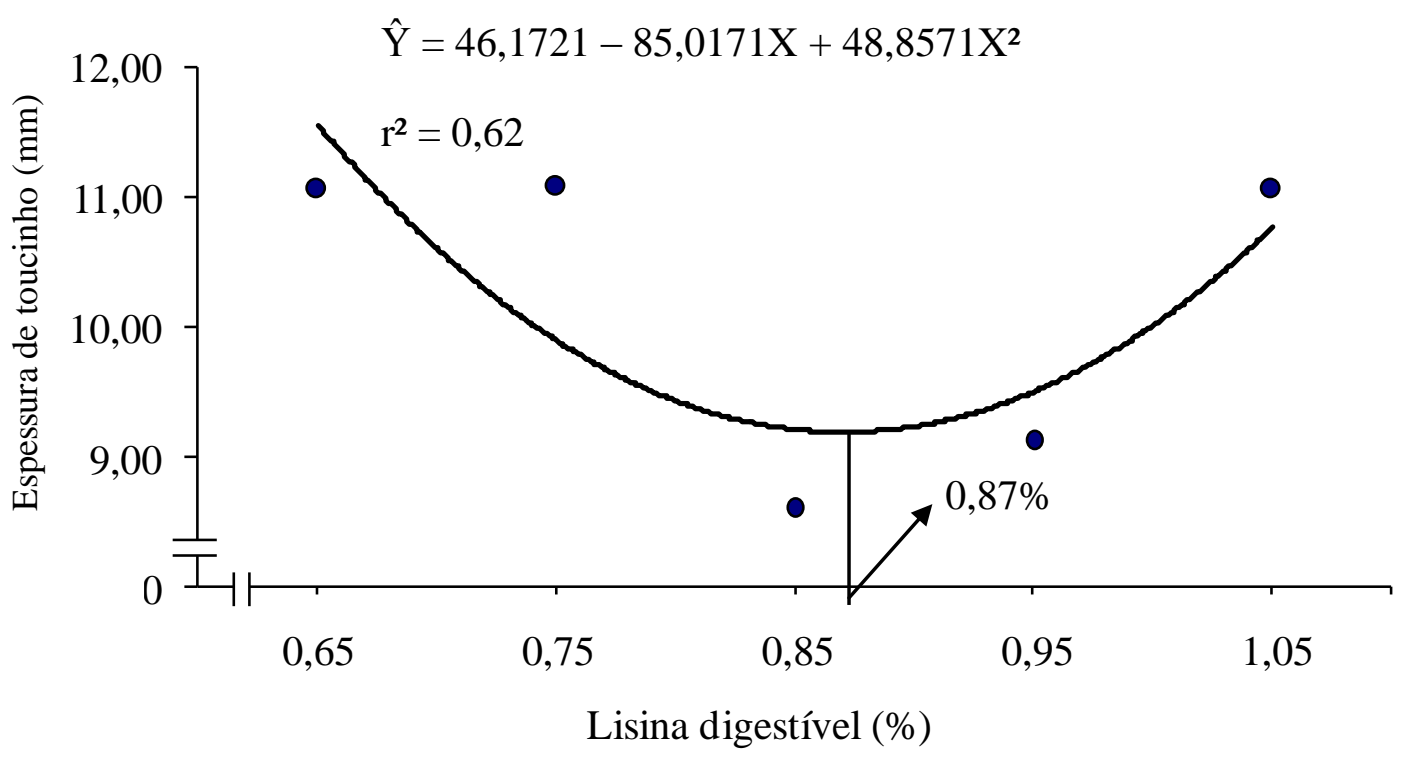

Figura 1. Representação gráfica do efeito da porcentagem de lisina na dieta sobre a espessura de toucinho de leitoas dos 60 aos 100 dias de idade.

Foi observada uma inconsistência nos resultados de espessura de toucinho no presente estudo, pois constatou-se aumento de $6,0 \%$ na ET dos animais quando se elevou a lisina digestível de 0,85 para $0,95 \%$, uma vez que, entre essas porcentagens de lisina, a quantidade de carne na carcaça aumentou de 23,35 para $24,68 \mathrm{~kg}$. Como

\section{CONCLUSÃO}

A inclusão de $1,05 \%$ de lisina digestível, correspondente ao consumo de lisina digestível de $18,46 \mathrm{~g} / \mathrm{dia}$, proporciona os melhores resultados de desempenho e quantidade de carne em leitoas com alto potencial genético para deposição de carne na carcaça, dos 60 aos 100 dias de idade. o consumo de energia digestível não variou entre os tratamentos, esperava-se uma redução na espessura de toucinho, em razão do maior gasto energético para a deposição de carne magra na carcaça, nos animais que consumiram dieta com $0,95 \%$ de lisina digestível em relação aos que consumiram dietas com $0,85 \%$.

\section{AGRADECIMENTOS}

À Perdigão S.A., pelo financiamento do projeto e apoio na realização dos trabalhos de campo, e à FESURV (Faculdade de Ensino Superior de Rio Verde, GO), por disponibilizar a estrutura física para a realização dos trabalhos de campo. 


\section{REFERÊNCIAS}

ABREU, M.L.T.; DONZELE, J.L.; OLIVEIRA, R.F.M. et al. Níveis de lisina digestível em rações, utilizando-se o conceito de proteína ideal, para suínos machos castrados de alto potencial genético, dos 30 aos 60kg. Rev. Bras. Zootec., v.36, p.62-67, 2007.

BATISTA, R.M., OLIVEIRA, R.F.M., DONZELE, J.L. et al. Lisina digestível para suínos machos castrados de alta deposição de carne submetidos a estresse por calor dos 30 aos $60 \mathrm{~kg}$. Rev. Bras. Zootec., v.40, p.1925-1932, 2011.

BAKER, D.H. Efficiency of amino acid utilization in the pig. IN: PROCEEDINGS OF THE FOURTH BIENNIAL CONFERENCE OF THE AUSTRALASIAN PIG SCIENCE ASSOCIATION (APSA), Canberra. p191-197. 1993.

COFFEY, R.D.; PARKER, G.R.; LAURENT, K.M. Feeding growing-finishing pigs to maximize lean grow rate. University of Kentucky. College of Agriculture, 2000. Disponível em: http://www.animalgenome.org/edu/PIH/prod_grow_ finish.pdf . Acessado em: 18 jul 2007.

D'MELLO, J.P.F. Amino acid supplementation of cereal-based diets for non-ruminants. Anim. Feed Sc. Tech., v.45, p.1-18, 1993.

DONZELE, J.L.; FREITAS, R.T.F.; OLIVEIRA, R.F.M. et al. Níveis de lisina para leitoas de 30 a 60 kg de peso vivo. Rev. Bras. Zootec., v.24, p.967-973, 1994.

FONTES, D.O.; DONZELE, J.L.; OLIVEIRA, R.F.M. et al. Níveis de lisina para leitoas selecionadas geneticamente para deposição de carne magra, dos 30 aos $60 \mathrm{~kg}$, mantendo constante a relação entre lisina e metionina + cistina, treonina, triptofano, isoleucina e valina. Rev. Bras. Zootec., v.29, p.776-783, 2000.

FONTES, D.O.; DONZELE, J.L.; OLIVEIRA, R.F.M. et al. Níveis de lisina para leitoas selecionadas geneticamente para deposição de carne magra na carcaça, dos 30 aos 60kg. Rev. Bras. Zootec., v.34, p.81-89, 2005

FRIESEN, K.G.; NELSSEN, J.L.; GOODBAND, R.D. et al. Influence of dietary lysine on growth and carcass composition of high-lean growth gilts fed from 34 to 72 kilograms. J. Anim. Sci., v.72, p.1761-1770, 1994.

HAESE, D.; SARAIVA, A.; DONZELE, J.L. et al. Exigência de lisina digestível para fêmeas suínas mestiças de duas linhagens comerciais dos 60 aos 100 dias de idade. In: CONGRESSO LATINOAMERICANO DE SUINOCULTURA, 3., 2006. Foz do Iguaçu. Anais... Foz do Iguaçú, 2006.
HAESE, D.; DONZELE, J.L.; OLIVEIRA, R.F.M. et al. Digestible lysine for barrows of genetic lines selected for meat deposition from 60 to 100 days of age. Rev. Bras. Zootec., v.40, p.1941-1946, 2011.

HAHN, J.D.; BIEHL, R.R.; BAKER, D.H. Ideal digestible lysine for early and late-finishing swine. $J$. Anim. Sci., v.73, p.3773-784, 1995.

HENRY, Y. Dietary factors involved in feed intake regulation in growing pigs: A Review. Liv. Prod. Sci., v.12, p.339-354, 1985.

NATIONAL research council - NRC. Comittee Animal Nutrition. Nutrient requirements of swine. 10 ed. Washingorn: National Academic Press, 1998. 189p.

ROSTAGNO, H.S.; ALBINO, L.F.T.; DONZELE, J.L. et al. Tabelas Brasileiras para Aves e Suínos: Composição de alimentos e exigências nutricionais. Viçosa, MG:UFV, 2005. 186p.

SILVA, F.C.O.; DONZELE, J.L.; OLIVEIRA, R.F.M. et al. Influência do número de animais e tipo de comedouro na unidade experimental sobre as exigências nutricionais e composição de carcaça de suínos em terminação. Rev. Bras. Zootec., v.38, p.1059-1067, 2009.

SOUZA, A.M. Exigências nutricionais de lisina para suínos mestiços, de 15 a $95 \mathrm{~kg}$ de peso. 1997. 81f. Dissertação (Mestrado em Zootecnia) - Universidade Federal de Viçosa, Viçosa, MG.

STAHLY, T.S.; CROMWELL, G.L.; TERHUNE, D. Responses of high, medium and low lean growth genotypes to dietary amino acid regimen. J. Anim. Sci., v.69, suppl. 1, p.364, 1991. (Abstr.).

STAHLY, T.S.; WILLIAMS, N.H.; SWENSON, N.H. Impact of genotype and dietary regimen on growth of pigs from 6 to $25 \mathrm{~kg}$. J. Anim. Sci., v.72, suppl. 1, p.165, 1994 .

SISTEMA para análise estatística e genética - SAEG, Viçosa, MG: Fundação Arthur Bernardes, 2009.

YEN, H.T.; COLE, D.J.A.; LEWIS, D. Amino acid requirements of growing pigs. 7 . The response of pigs from 25 to $35 \mathrm{~kg}$ live weight to dietary ideal protein. Anim. Prod., v.43, p.141-154, 1986. 